\title{
Nesfatin-1 prevents negative changes in bone in conditions of developing osteopenia
}

\author{
Iwona Puzio, ${ }^{1, A-F \oplus}$, Grzegorz Tymicki ${ }^{1, A-F \oplus}{ }^{\oplus}$, Marta Pawłowska-Olszewska ${ }^{1, B-E \oplus}$, Marek Bieńko ${ }^{1, B-C \oplus,}$, \\ Radosław Piotr Radzki ${ }^{1, \mathrm{~B}-\mathrm{C} \oplus \mathrm{C}}$ \\ 1 University of Life Sciences, Lublin, Poland \\ A - Research concept and design, B - Collection and/or assembly of data, C - Data analysis and interpretation, \\ $D$ - Writing the article, E - Critical revision of the article, F - Final approval of article
}

\begin{abstract}
Puzio I, Tymicki G, Pawłowska-Olszewska M, Bieńko M, Radzki RP. Nesfatin-1 prevents negative changes in bone in conditions of developing
\end{abstract} osteopenia. Ann Agric Environ Med. 2020; 27(1): 66-75. doi: 10.26444/aaem/105981

\begin{abstract}
I Abstract
Objective. The aim of the study was to determine the effect of nesfatin-1 on bone properties in female rats in the conditions of developing osteopenia induced by ovariectomy (OVX).

Materials and method. The experiment was performed on 21 female Wistar rats assigned to 3 groups receiving intraperitoneally physiological saline (SHO, OVX-PhS) and nesfatin-1 in dose $2 \mu \mathrm{g} / \mathrm{kg}$ BW of (OVX-NES) once a day for 8 wks. At the end of the experiment, the rats were scanned using the DXA method to determine the body composition, tBMC, and tBMD. The isolated femora and tibia were tested with the DXA method for BMD and BMC, and with the PQCT method for separate analysis of the cortical and trabecular bone tissue. The bone strength parameters were also determined. The immunohistochemical method was used for determination of nesfatin-1 localization in growth cartilage. Bone metabolism markers (osteocalcin, bALP, and NTx) were identified using an ELISA kit.

Results. OVX exerts a negative effect on bone tissue. The nesfatin-1 administration influenced positively the DXA parameters of tibia. TvBMD and TbvBMD measured by $\mathrm{PQCT}$ in metaphysis of bones were significantly higher in the OVX-NES group than in OVX-PhS. No differences were found in the values of bone strength parameters between SHO and OVX-NES females. Extra- and intracellular immunohistochemical reaction for nesfatin-1 was observed in all zones of growth cartilage, with the strongest reaction detected in the calcifying zone. Nesfatin-1 administration caused a significant increase in the osteocalcin and bALP concentration in relation to the OVX-PhS animals.

Conclusion. The results of the experiment indicate that nesfatin-1 exerts a protective effect on bone tissue properties and can be used in the prevention of osteoporosis.
\end{abstract}

I Key words

nesfatin-1, osteopenia, osteoporosis, ovariectomy, rat, DXA, PQCT, immunohistochemistry

\section{INTRODUCTION}

The skeletal system of humans and animals undergoes remodeling over the entire lifetime, including osteoblastic bone formation and osteoclastic resorption. During aging, bone resorption intensifies, which leads to a gradual physiological loss of bone mass and osteopenic changes. However, osteopenia may be more pronounced and lead to osteoporosis (OP). According to the WHO definition, $\mathrm{OP}$ is a systemic disease characterized by a progressive loss of bone mass and disturbances in bone microarchitecture leading to reduction of its strength. OP has manifold basis, but the most common cause is the decrease in the level of sex hormones - estrogens and androgens, progressing with age $[1,2]$. Reduction in the level of these hormones induces an increase in bone turnover with stronger severity of bone resorption, consequently causing a gradual loss of bone mass $[2,3,4]$.

Currently, OP is considered a civilization disease in highly developed societies. OP can result in fractures, re-fractures, reduction or loss of mobility, decreased independence, lowered self-esteem, and increasing costs of treatment. Moreover, osteoporotic fractures may lead to serious complications,

Address for correspondence: Iwona Puzio, University of Life Sciences in Lublin Poland

E-mail: iwona.puzio@up.lublin.pl

Received: 19.01.2019; accepted: 20.03.2019; first published: 02.04.2019 mainly cardiovascular, respiratory, and gastrointestinal disorders, and death. Thus, OP involves a huge personal and economic burden $[5,6,7]$. Due to the high health, social, and economic costs of $\mathrm{OP}$, it is necessary to conduct research to determine the various physiological factors that may affect the bone tissue.

Recent studies indicate that different adipokines, e.g. leptin, adiponectin, resistin, and visfatin, have an effect on the skeletal system [8-17]; their action, however, is not explicit and fully understood. One of the adipokines is NUCB-2/ nesfatin-1 discovered in 2006 by Oh-I et al. [18]. Nesfatin-1 is derived from protein called nucleobindin-2 (NUCB-2), which has the ability to attach $\mathrm{Ca}^{2+}$ and DNA. In the presence of the prohormone convertase (PC)-1/3, NUCB-2 forms three peptides: nesfatin-1 (residues 1-82), nesfatin-2 (residues 85-163), and nesfatin-3 (residues 166-396). Studies have shown that only nesfatin-1 has biological activity $[18,19]$.

The first studies on the effect of nesfatin- 1 on bone and cartilage originate from 2013, and later. Expression of the nesfatin-1 gene has been demonstrated in joint cartilage, osteophytes, meniscus, synovium, and infrapatellar fat pads of healthy and osteoarthritis (OA) cartilage [20]. The higher expression of nesfatin-1 mRNA and the stronger immunohistochemical reaction for nesfatin-1 in OA cartilage, compared to healthy cartilage, indicate that nesfatin-1 may participate in the pathogenesis of OA. This can be confirmed by the significantly higher serum nesfatin-1 
level in patients with OA $[20,21]$ and the increase in the nesfatin-1 concentration in synovial fluid progressing with the development of OA [21].

In addition, a correlation was observed between the serum concentration of nesfatin-1 and the high-sensitivity C-reactive protein (hsCRP), as well as the level of nesfatin-1 and interleukin-18 (IL- 18) in synovial fluid in patients with OA [20]. Because IL-18 and hsCRP are associated with the development of cartilage inflammation $[22,23]$, these correlations may confirm the participation of nesfatin-1 in the pathogenesis of $\mathrm{OA}$ and suggest that it may be used as an OA marker. The participation of nesfatin-1 in the pathogenesis of OA is also supported by in vitro studies. It was shown that NUCB2/nesfatin-1 mRNA and protein were expressed in human primary OA chondrocytes and murine chondrocytes ATD-5 [24]. In these cells, nesfatin-1 induces chemotactic and pro-inflammatory mediators, i.e. interleukin-8 (IL-8), interleukin-6 (IL-6), cyclooxygenase-2 (COX-2), and macrophage inflammatory protein-1a (MIP-1a). This effect is exerted by nesfatin-1 alone or in combination with interleukin-1 (IL-1) [24]. In turn, IL-1 and tumour necrosis factor- $\alpha$ (TNF- $\alpha$ ) increase mRNA expression and NUCB2/nesfatin-1 synthesis in human primary and mouse differentiated chondrocytes [24].

Expression of NUCB2/nesfatin-1 mRNA was also found in osteoblastic and osteoclastic cell lines in in vitro studies [25]. It was shown that NUCB2/nesfatin-1 increased alkaline phosphatase activity (ALP) in murine preosteoblastic cells in a dose-dependent manner, but this effect was dependent on recombinant human bone morphogenetic protein-2 (rhBMP2), because nesfatin-1 alone showed no direct effect on ALP activity. Nevertheless, nesfatin-1 stimulated mineralization without the addition of rhBMP-2. Moreover, it inhibited the differentiation of macrophages towards osteoclasts (OC), thus limiting osteoclastogenesis [25]. The only available in vivo study showed a positive effect of intravenous administration of nesfatin-1 on bone tissue manifested by an increase in the mineral density of femurs and lumbar vertebrae in gonadectomized female rats [25].

Taken together, data concerning the interaction of nesfatin-1 with skeletal system tissues are very limited and inconsistent. However, it can be assumed that nesfatin-1 may be a protective physiological factor for bone. Hence, the main objective of the study is to determine whether nesfatin-1 influences bone metabolism in vivo and can be used in the prevention of OP. The effect of exogenous nesfatin-1 on bone tissue will be assessed in conditions of developing osteopenia induced by surgical elimination of the endocrine function of ovaries in female rats.

\section{MATERIALS AND METHOD}

The research was carried out with the approval of the Local Ethics Committee for animal experiments at the University of Life Sciences in Lublin, Poland. All experiments complied with the Guiding Principles for Research Involving Animals.

The studies were conducted on 21 female Wistar rats, aged approximately 3 months, with initial body weight (BW) 210-230 g. Throughout the experiments, the animals were maintained in standard environmental conditions (temperature $22^{\circ} \mathrm{C} \pm 2{ }^{\circ} \mathrm{C}$, day/night cycle $12 \mathrm{~h} / 12 \mathrm{~h}$ ), humidity
$55 \% \pm 5 \%$ ), with constant access to water and feed (LSM, Agropol, Motycz, Poland).

After 7 days of acclimatization, the animals were randomly divided into 2 groups. The animals of the first group underwent pseudogonadectomy surgery $(\mathrm{SHO}, \mathrm{n}=7)$. In the second group, ovariectomy was performed (OVX, $n=14$ ). The abdominal wall was cut in the white line along the length of approx. $8 \mathrm{~mm}$. Ovaries were isolated from the peritoneal cavity, carefully isolated from the uterine horns, ligated, and finally removed. Surgical procedures were performed under general anesthesia using intramuscular injection of ketamine (Biowet-Pulawy, Poland), atropinum sulphuricum (PolfaWarszawa, Poland), and xylazine (Biowet-Pulawy, Poland) at doses of $3 \mathrm{mg} / \mathrm{kg} \mathrm{BW}, 0.05 \mathrm{mg} / \mathrm{kg} \mathrm{BW}$, and $10 \mathrm{mg} / \mathrm{kg} \mathrm{BW}$, respectively. Immediately after surgery, the animals were placed individually in cages for a period of 7 days to reduce the risk of postoperative complications and fatalities. After this period, 3-4 animals were placed in each cage. After 7-day postoperative recovery, the OVX animals were randomly divided into 2 groups of 7 individuals in each, which received intraperitoneal injection of physiological saline (OVX-PhS) or nesfatin-1 (Phoenix Pharmaceuticals, Inc., Burlingame, CA, USA) at a dose of $2 \mu \mathrm{g} / \mathrm{kg}$ (OVX-NES) once a day for 8 weeks. Before use, nesfatin-1 was dissolved in physiological saline $(0.1 \mathrm{ml} \mathrm{PhS}-0.2 \mu \mathrm{g}$ nesfatin-1). Animals subjected to the sham operation ( $\mathrm{SHO}$ ) received physiological saline for 8 weeks. Animals from the OVX-PhS and SHO groups received physiological saline in a similar volume as the OVXNES solution of nesfatin-1. Nesfatin-1 and physiological saline were administered between 10:00-12:00. In order to determine the amount of administered nesfatin-1, the BW of the animals was monitored every 2 days.

After an 8-wk period of nesfatin-1 or physiological saline administration, and after a 12-hour night fasting with access to water, the animals were weighed to assess BW and then euthanized by $\mathrm{CO}_{2}$ overdose. Blood was collected via intraventricular puncture into sample tubes containing a coagulation activator for further analysis of serum. The animals were then euthanized by cervical dislocation. Immediately after euthanasia, densitometric measurements of the body composition were performed. Subsequently, the femur and tibia were isolated, stripped of soft tissues, and secured for immunohistochemical examination in $4 \%$ formaldehyde solution (left femur), or at $-20^{\circ} \mathrm{C}$ for further densitometric, tomographic, and mechanical analyses (right femur and tibia).

Bone densitometric analysis (DXA). Densitometric measurements were made using the dual energy X-ray absorption method (DXA) with the use of the Norland Excel Plus apparatus (Fort Atkinson, WI, USA) and the Small Subject Scan 4.4.1 programme. Whole bodies of rats were analyzed to determine lean mass (LM), fat mass (FM), total mineral density (tBMD), and total mineral content (tBMC) of skeletons. The isolated right femur and tibia were subjected to assessment of mineral density (BMD) and mineral content (BMC). The speed of prescan was set at $100 \mathrm{~mm} / \mathrm{s}$ at a $1.5 \times 1.5 \mathrm{~mm}$ prescan resolution. The speed of the proper scan was $30 \mathrm{~mm} / \mathrm{s}$, resolution $-1.0 \times 1.0 \mathrm{~mm}$. The densitometer was calibrated before each measurement session using a hydroxyapatite phantom provided by the manufacturer. 
Bone tomographic analysis (pQCT). Tomographic examination of isolated bones was performed using highresolution peripheral quantitative computed tomography (pQCT) (XT Research SA Plus, Stratec Medizintechnik, $\mathrm{GmbH}$, Pforzheim, Germany) and Stratec 6.2.C software. The bone cross-section and trabecular and cortical bone tissue were analyzed. After the initial scanning, carried out at $10 \mathrm{~mm} / \mathrm{s}$, the region to be analyzed was determined. Examination of the trabecular bone was carried out in the distal metaphysis of the femur ( $5 \mathrm{~mm}$ from the surface of the knee-joint) and in the proximal metaphysis of the tibia $(5 \mathrm{~mm}$ from the proximal end). The threshold for trabecular bone was determined to be $0.630 \mathrm{~cm}^{-1}$. Analysis of femur and tibia cortical bone was performed at half their length, threshold factor $-0.790 \mathrm{~cm}^{-1}$. After setting the appropriate measurement parameters, proper scanning was carried out at a speed of $4 \mathrm{~mm} / \mathrm{min}$. The device was calibrated using a hydroxyapatite phantom according to the procedure recommended by the manufacturer. The following parameters of the total cross-section of the femur and tibia, as well as the cortical bone at $50 \%$ of the bone length, were determined: Total Bone Mineral Content (TotBMC), Total Mineral Density (TotBMD), Cortical Bone Mineral Content (CtBMC), Cortical Bone Mineral Density (CtBMD), Total Area (TotA), Cortical Area (CtrA), Cortical Thickness (CtrTh), Peripheral Circumference (Peri.C), Endocortical Circumference (Endo.C), and Strenght Strain Index (SSI). For trabecular bone in distal femoral metaphysis and proximal tibial metaphysis, the parameters examined included: Total Bone Mineral Content (TotBMC), Total volumetric Mineral Density (TotvBMD), Trabecular Bone Mineral Content (TbBMC), Trabecular Bone Mineral Density (TbBMD), Total Area (TotA), and Trabecular Area (TbA).

Bone mechanical analysis. After the densitometric and tomographic analyses, the isolated femur and tibia were subjected to a 3-point bending test, according to Feretti et al. [26] using a Zwick-Roell Testing Machine Z010 (ZwickRoell GmbH \& Co. KG, Ulm, Germany) connected to the computer registering the relationship between force acting perpendicular to the long axis of the bone and deformation. A measuring head $0-10 \mathrm{KN}$ (Xforce HD) moving at a constant speed of $10 \mathrm{~mm} / \mathrm{min}$ was used in the tests. The bones were placed on 2 supports with a spacing corresponding to $40 \%$ of the bone length. The obtained results were analyzed with testXpert II 3.1 software (Zwick-Roell GmbH \& Co. KG, Ulm, Germany). The following bone strength parameters were assessed: ultimate strength, relationship of work to ultimate strength, and Young's modulus.

Immunohistochemical staining. The isolated left femurs stripped of soft tissues were fixed in $4 \%$ buffered formaldehyde, rinsed in water, and then decalcified in a disodium edetate solution (Eurochem BGD S.A., Poland). After decalcification, the bones were rinsed in water and then placed in 50\% and $70 \%$ ethanol solutions. In the next stage, the samples were dehydrated and processed using a tissue processor (Microm STP 120, Microm International GmbH, Germany) and the Ottix Shaper and Ottix Plus reagents (Diapath, Microstain Division, Via Savoldini, Martinengo, Italy). The samples were immersed in paraplast (Sigma-Aldrich $\mathrm{GmbH}$, Steinheim, Germany) and then embedded in paraplast in the form of blocks that were cut into $4-\mu \mathrm{m}$ thick sections with a microtome (Microm HM 355, Microm International
GmbH, Germany). The slides were then deparaffinised using xylene, and then hydrated in a range of ethyl alcohol solutions with decreasing concentrations up to distilled water. The samples were rinsed in buffered saline (PBS) and then incubated in a solution of $3 \%$ hydrogen peroxide in order to inactivate the tissue enzyme and thus prevent the nonspecific reaction. In the next stage, controlled digestion at $37^{\circ} \mathrm{C}$ using a proteolytic enzyme (Proteinase K, Cell Marque Corporation, Rocklin, California, USA) was carried out, aimed at restoring antigens to their original characteristics. Afterwards, the samples were incubated with Ultravision Protein Block reagent (Thermo Fisher Scientific, Waltham, Massachusetts, USA) containing immunologically inactive bovine serum, preventing the occurrence of unspecific reactions. Subsequently, incubation with anti-nesfatin-1 primary antibodies [Nesfatin-1 (1-82) (Rat) Antibody, Phoenix Pharmaceuticals, Inc. Burlingame, CA, USA] was carried out in a humid chamber at room temperature for 1 hour. The antibodies were diluted in PBS at a ratio of 1:2,000 before use. Further labelling steps were performed using the UltraVision Quanto Detection System (Thermo Fisher Scientific, Waltham, Massachusetts, USA) and DAB Quanto (Thermo Fisher Scientific, Waltham, Mass., USA), according to the manufacturer's instructions. In addition, the preparations were stained with Mayer's haematoxylin (Thermo Fisher Scientific, Waltham, Massachusetts, USA) to visualize cell nuclei. A negative control was performed with the omission of the primary antibodies. After completion of the immunohistochemical reactions, the samples were dehydrated in ethanol, xylaned, and closed in DPX (Fluka Chemie GmbH, Switzerland). The obtained specimens were photographed using a Zeiss Axioskop $40 \mathrm{FL}$ microscope with a magnification of 400x. The location of cells showing a positive immunohistochemical reaction for nesfatin-1 and the intensity of the immunohistochemical reaction were examined in the growth cartilage. The following scale was used to assess the semi-quantitative intensity of the immunohistochemical reaction: (+/-) - slight immunoreactivity, $(+)$ - medium immunoreactivity, $(++)-$ high immunoreactivity, (+++) - very high immunoreactivity.

Blood biochemical analysis. The measurements of bone metabolism markers in serum were performed using commercial ELISA kits: osteocalcin [Rat Osteocalcin/Bone gla protein (OT/BGP) ELISA kit, Sunred Biotechnology Company, Shanghai, China], bone alkaline phosphatase (bALP) [Rat bone alkaline phosphatase (BALP) ELISA kit, Sunred Biotechnology Company, Shanghai, China], and $\mathrm{N}$-terminal crosslinked telopeptide type I collagen (NTx) [Rat cross-linked N-telopeptide of type I collagen (NTx) ELISA kit, Sunred Biotechnology Company, Shanghai, China]. The assessment of the concentration of bone metabolism markers was carried out using a Benchmark Plus microplate spectrophotometer with Microplate Manager Software ver. 5.2.1. (Bio-Rad Laboratories Inc., Hercules, LA, USA).

Statistical analysis. The obtained results were subjected to statistical analysis and the values of the analyzed parameters presented in the form of mean values, together with the standard error of the mean (mean \pm S.E.M.). Statistically significant differences were assumed for the mean results at $P \leq 0.05$. Statistical analysis of the results was carried out in the STATISTICA 13.1 programme (StatSoft, Inc., Tulsa, 
Oklahoma, USA). Differences between the means were tested using the one-way analysis of ANOVA variance and the Tukey post-hoc test.

\section{RESULTS}

Body weight, bone mass and length. Assessment of BW of the rats after 8 weeks of physiological saline and nesfatin-1 administration showed statistically significantly lowest values of this parameter $(239.9 \pm 4.94 \mathrm{~g})$ in the SHO group $(\mathrm{P} \leq 0$ 05). Similar values of BW were observed in the OVXNES $(274.4 \pm 5.07 \mathrm{~g})$ and OVX-PhS $(280.1 \pm 10.33 \mathrm{~g})$ groups. There were no statistically significant differences in the mass and length of femur and tibia between the groups (data not shown).

Densitometric parameters. The results of densitometric analysis of the body composition, whole skeleton, and isolated bones are presented in Table 1. The ovariectomized group receiving nesfatin-1 (OVX-NES) was characterized by a significantly higher mean value of $\mathrm{LM}(\mathrm{P} \leq 0.05)$, compared to the SHO and OVX-PhS groups. There were no statistically significant differences in LM between the SHO and OVX-PhS groups, despite the fact that LM in OVX-PhS was greater. The OVX-PhS group was characterized by significantly higher values of FM (by approx. 8.6\%) in relation to the SHO and OVX-NES groups. Ovariectomy caused reduction of tBMD values of the whole skeleton by $5.42 \%$ (OVX-PhS) and 4.19\% (OVX-NES), compared to SHO. The analysis of tBMC did not show statistically significant differences in the values of this parameter between the individual groups. The highest $\mathrm{BMD}$ and $\mathrm{BMC}$ values of the femur and tibia were found in the sham-operated animals. Ovariectomy caused statistically significant reduction in $\mathrm{BMD}$ and $\mathrm{BMC}$ for both bones in the OVX-PhS females $(\mathrm{P} \leq 0.05)$. The $\mathrm{BMD}$ and $\mathrm{BMC}$ values of the femur in the OVX-NES females showed no statistically significant differences, compared to the SHO and OVX-PhS groups. In turn, the BMD and BMC values of the tibia in the OVX-NES females were higher than in the OVX-PhS group, and lower in comparison to the SHO group $(\mathrm{P} \leq 0,05)$.

Table 1. Parameters of body composition and densitometric parameters of whole skeleton and isolated bone of female rats in conditions of developing osteopenia

\begin{tabular}{|c|c|c|c|}
\hline Parameters & $\mathrm{SHO}$ & OVX-PhS & OVX-NES \\
\hline LM (g) & $20.01 \pm 5.24$ & $32.17 \pm 5.09$ & $55.24 \pm 6.54$ *\$ \\
\hline $\mathrm{FM}(\mathrm{g})$ & $203.2 \pm 6.05$ & $220.7 \pm 6.46 *$ & $203.5 \pm 5.66^{\S}$ \\
\hline tBMC (g) & $7.586 \pm 0.2303$ & $7.8580 \pm 0.1558$ & $8.2303 \pm 0.1309$ \\
\hline $\mathrm{tBMD}\left(\mathrm{g} / \mathrm{cm}^{2}\right)$ & $0.1457 \pm 0.0019$ & $0.1378 \pm 0.0019 *$ & $0.1396 \pm 0.0011 *$ \\
\hline \multicolumn{4}{|c|}{ Femur } \\
\hline BMC (g) & $0.3486 \pm 0.0076$ & $0.3316 \pm 0.0051 *$ & $0.3274 \pm 0.0056$ \\
\hline $\mathrm{BMD}\left(\mathrm{g} / \mathrm{cm}^{2}\right)$ & $0.1185 \pm 0.0018$ & $0.1053 \pm 0.0007 *$ & $0.1079 \pm 0.0005$ \\
\hline \multicolumn{4}{|c|}{ Tibia } \\
\hline $\mathrm{BMC}(\mathrm{g})$ & $0.2609 \pm 0.0062$ & $0.2297 \pm 0.0031$ * & $0.2331 \pm 0.0029 * \S$ \\
\hline $\mathrm{BMD}\left(\mathrm{g} / \mathrm{cm}^{2}\right)$ & $0.0943 \pm 0.0016$ & $0.0833 \pm 0.0007 *$ & $0.0861 \pm 0.0005 * \S$ \\
\hline
\end{tabular}

Tomographic parameters. The analysis conducted using pQCT demonstrated higher values of TotBMC and TbBMC of the distal femoral metaphysis in the SHO group, compared to the OVX-PhS and OVX-NES groups $(\mathrm{P} \leq 0.05)$ (Tab. 2). Similar values of these parameters were observed in both ovariectomized groups. Ovariectomy significantly also reduced TotvBMD and TbBMD of femoral metaphysis in both groups (Tab. 2). However, the lowest TotvBMD and TbBMD values showing statistical significance in comparison to the other groups were found in the OVX-PhS females. Nesfatin-1 administration to the ovariectomized rats significantly increased the values of TotvBMD and TbBMD, compared to the OVX-PhS group, i.e. by $3.66 \%$ and $24 \%$, respectively $(\mathrm{P} \leq 0.05)$. There were no statistically significant differences in the mean values of TotA and TbA of the distal metaphysis of the femur between the individual groups (Tab. 2). The pQCT analysis of the cross-section of the shaft and the cortical bone tissue of the femur revealed statistically significant differences between the examined groups only in relation to the CtBMD, with the lowest value determined in the OVX-PhS group $(\mathrm{P} \leq 0.05)$ (Tab. 2). The femur CtBMD values of the SHO and OVX-NES rats were similar. There were no statistically significant differences in the values of TotBMC, TotBMD, CtBMC, TotA, CtrA, CtrTh, Peri.C, Endo.C, and SSI between the analyzed groups.

Table 2. Parameters of cross-section and trabecular and cortical bone tissue of femur of female rats in conditions of developing osteopenia

\begin{tabular}{cccc}
\hline Parameters & SHO & OVX-PhS & OVX-NES \\
\hline Distal metaphysis & & & \\
\hline TotBMC $(\mathrm{mg} / \mathrm{mm})$ & $13.43 \pm 0.479$ & $9.55 \pm 0.406^{*}$ & $8.91 \pm 0.322{ }^{*}$ \\
\hline TotvBMD $\left(\mathrm{mg} / \mathrm{mm}^{3}\right)$ & $864 \pm 18.87$ & $573 \pm 10.63 \mathrm{~b}{ }^{*}$ & $594 \pm 10.03 *$ \\
\hline TbBMC $\left(\mathrm{mg} / \mathrm{mm}^{*}\right)$ & $4.11 \pm 0.233$ & $1.46 \pm 0.254^{*}$ & $1.79 \pm 0.236^{*}$ \\
\hline TbBMD $\left(\mathrm{mg} / \mathrm{mm}^{3}\right)$ & $586 \pm 20.35$ & $191 \pm 17.98^{*}$ & $238 \pm 20.15^{*}$ \\
\hline TotA $\left.(\mathrm{mm})^{2}\right)$ & $15.55 \pm 0.528$ & $16.64 \pm 0.512$ & $16.69 \pm 0.362$ \\
\hline TbA $\left.(\mathrm{mm})^{2}\right)$ & $6.99 \pm 0.237$ & $7.48 \pm 0.277$ & $7.44 \pm 0.465$ \\
\hline Diaphysis & & & \\
\hline TotBMC $\left(\mathrm{mg} / \mathrm{mm}^{*}\right)$ & $7.9 \pm 0.128$ & $7.6 \pm 0.112$ & $7.86 \pm 0.095$ \\
\hline TotBMD $\left(\mathrm{mg} / \mathrm{mm}^{3}\right)$ & $967 \pm 8.75$ & $953 \pm 11.29$ & $949 \pm 7.78$ \\
\hline CtBMC $\left(\mathrm{mg} / \mathrm{mm}^{*}\right)$ & $7.54 \pm 0.106$ & $7.14 \pm 0.170$ & $7.47 \pm 0.082$ \\
\hline CtBMD $\left(\mathrm{mg} / \mathrm{mm}^{3}\right)$ & $1445 \pm 1.65$ & $1429 \pm 3.69 \mathrm{~b} *$ & $1446 \pm 5.11^{\S}$ \\
\hline TotA $\left(\mathrm{mm}{ }^{2}\right)$ & $8.18 \pm 0.161$ & $8.06 \pm 0.096$ & $8.28 \pm 0.102$ \\
\hline CtrA $\left(\mathrm{mm}{ }^{2}\right)$ & $5.21 \pm 0.071$ & $4.99 \pm 0.116$ & $5.16 \pm 0.049$ \\
\hline CtrTh $(\mathrm{mm})$ & $0.64 \pm 0.009$ & $0.61 \pm 0.017$ & $0.63 \pm 0.007$ \\
\hline Peri.C $(\mathrm{mm})$ & $10.14 \pm 0.098$ & $10.06 \pm 0.059$ & $10.20 \pm 0.063$ \\
\hline Endo.C $(\mathrm{mm})$ & $6.09 \pm 0.125$ & $6.20 \pm 0.114$ & $6.25 \pm 0.092$ \\
\hline SSI $\left(\mathrm{mm}{ }^{3}\right)$ & $5.63 \pm 0.141$ & $5.22 \pm 0.236$ & $5.71 \pm 0.132$ \\
\hline
\end{tabular}

Data are mean \pm S.E.M for 7 animals. Statistical significance is indicated as ${ }^{*} \mathrm{P}<0.05 \mathrm{vs}$. SHO; ${ }^{\S}$ vs. OVX-PhS at $\mathrm{P} \leq 0.05$

The proximal metaphysis of the tibia in the SHO group was characterized by the significantly highest values of TotBMC, TbBMD, and TotvBMD, in comparison to both ovariectomized groups ( $\mathrm{P} \leq$ 0.05) (Tab. 3). Moreover, ovariectomy significantly reduced the TbBMC values of the proximal metaphysis of the tibia $(\mathrm{P} \leq 0.05)$ in the OVX-PhS females, compared to the SHO females (Tab. 3). The lowest values of the above-mentioned parameters were determined in the OVX-PhS group. Nesfatin-1 administration induced a significant $(\mathrm{P} \leq 0.05)$ increase in the TotvBMD and TbBMD values in comparison to the OVX-PhS group, i.e. by $24.7 \%$ and 
Table 3. Parameters of cross-section and trabecular and cortical bone tissue of tibia of female rats in conditions of developing osteopenia

\begin{tabular}{|c|c|c|c|}
\hline Parameters & $\mathrm{SHO}$ & OVX-PhS & OVX-NES \\
\hline \multicolumn{4}{|l|}{ Proximal metaphysis } \\
\hline TotBMC (mg/mm) & $14.43 \pm 0.260$ & $8.25 \pm 0.288 *$ & $8.87 \pm 0.385 *$ \\
\hline $\operatorname{TotvBMD}\left(\mathrm{mg} / \mathrm{mm}^{3}\right)$ & $851 \pm 18.66$ & $555 \pm 8.27 *$ & $692 \pm 14.96 * 8$ \\
\hline TbBMC (mg/mm) & $3.21 \pm 0.136$ & $0.98 \pm 0.118 b^{*}$ & $1.3 \pm 0.254$ \\
\hline $\mathrm{TbBMD}\left(\mathrm{mg} / \mathrm{mm}^{3}\right)$ & $532 \pm 24.3$ & $144 \pm 13.95 *$ & $190 \pm 13.89 * 5$ \\
\hline TotA $\left(\mathrm{mm}^{2}\right)$ & $13.43 \pm 0.171$ & $14.89 \pm 0.473$ & $14.96 \pm 0.350$ * \\
\hline $\mathrm{TbA}\left(\mathrm{mm}^{2}\right)$ & $6.04 \pm 0.076$ & $6.7 \pm 0.214$ & $6.74 \pm 0.157 *$ \\
\hline \multicolumn{4}{|l|}{ Diaphysis } \\
\hline TotBMC $(\mathrm{mg} / \mathrm{mm})$ & $5.22 \pm 0.803$ & $5.29 \pm 0.126$ & $5.29 \pm 0.099$ \\
\hline TotBMD $\left(\mathrm{mg} / \mathrm{mm}^{3}\right)$ & $1063 \pm 10.14$ & $1066 \pm 5.359$ & $1068 \pm 14.88$ \\
\hline $\mathrm{CtBMC}(\mathrm{mg} / \mathrm{mm})$ & $4.99 \pm 0.071$ & $4.96 \pm 0.110$ & $5.0 \pm 0.093$ \\
\hline $\mathrm{CtBMD}\left(\mathrm{mg} / \mathrm{mm}^{3}\right)$ & $1410 \pm 4.727$ & $1394 \pm 7.327$ & $1409 \pm 3.721$ \\
\hline $\operatorname{Tot} \mathrm{A}\left(\mathrm{mm}^{2}\right)$ & $4.91 \pm 0.095$ & $4.96 \pm 0.127$ & $4.96 \pm 0.156$ \\
\hline $\mathrm{CtrA}\left(\mathrm{mm}^{2}\right)$ & $3.54 \pm 0.045$ & $3.56 \pm 0.067$ & $3.55 \pm 0.074$ \\
\hline CtrTh (mm) & $0.59 \pm 0.008$ & $0.58 \pm 0.005$ & $0.59 \pm 0.006$ \\
\hline Peri.C (mm) & $7.85 \pm 0.075$ & $7.89 \pm 0.100$ & $7.88 \pm 0.125$ \\
\hline Endo.C (mm) & $4.13 \pm 0.108$ & $4.20 \pm 0.095$ & $4.19 \pm 0.140$ \\
\hline $\mathrm{SSI}\left(\mathrm{mm}^{3}\right)$ & $2.79 \pm 0.079$ & $2.74 \pm 0.115$ & $2.77 \pm 0.118$ \\
\hline
\end{tabular}

Data are mean \pm S.E.M for 7 animals. Statistical significance is indicated as ${ }^{*} \mathrm{P}<0.05$ vs. $\mathrm{SHO}$ ${ }^{\S}$ vs. OVX-PhS at $\mathrm{P} \leq 0.05$

$31.9 \%$, respectively (Tab. 3). Furthermore, nesfatin-1 given to the OVX rats significantly $(\mathrm{P} \leq 0.05)$ increased the TotA and $\mathrm{TbA}$ of the proximal tibial metaphysis in comparison to the $\mathrm{SHO}$ rats. Analysis of the total bone cross-section and cortical bone parameters of the tibia shaft, i.e. TotBMC, TotBMD, CtBMC, CtBMD, TotA, CtrA, CtrTh, Peri.C, Endo.C, and SSI, did not show statistically significant differences between the particular groups.

Based on the results obtained in the 3-point bending test, it was found that the OVX-PhS group was characterized by the lowest values of ultimate strength of the femur $(\mathrm{P} \leq 0.05)$ (Tab. 4). The mean values of this parameter were lower by about $26 \%$ in relation to the SHO and OVX-NES groups. The results of Young's modulus measurements and the work-toultimate strength ratio did not show statistically significant differences between the study groups; however, a downward tendency was observed in the OVX-PhS group (Tab. 4). The values of the mechanical parameters of the femur in the SHO and OVX-NES animals were similar. The lowest values of the

Table 4. Mechanical parameters of femur and tibia of female rats in conditions of developing osteopenia

\begin{tabular}{|c|c|c|c|}
\hline Parameters & $\mathrm{SHO}$ & OVX-PhS & OVX-NES \\
\hline \multicolumn{4}{|l|}{ Femur } \\
\hline Young's modulus (GPa) & $4.579 \pm 0.339$ & $3.762 \pm 0.367$ & $4.136 \pm 0.289$ \\
\hline Ultimate strength $(\mathrm{N})$ & $118.46 \pm 7.88$ & $87.27 \pm 10.75 *$ & $117.79 \pm 3.84^{\S}$ \\
\hline Work/ultimate strength $(\mathrm{N} \times \mathrm{mm})$ & $25.81 \pm 3.25$ & $18.81 \pm 2.265$ & $27.197 \pm 1.157$ \\
\hline \multicolumn{4}{|l|}{ Tibia } \\
\hline Young's modulus (GPa) & $7.46 \pm 1.712$ & $10.2 \pm 1.415$ & $11.42 \pm 1.202$ \\
\hline Ultimate strength (N) & $93.55 \pm 6.303$ & $69.27 \pm 9.033 *$ & $73.92 \pm 3.649$ \\
\hline Work/ultimate strength $(\mathrm{N} \times \mathrm{mm})$ & $27.91 \pm 2.714$ & $13.91 \pm 1.306 *$ & $16.502 \pm 4.697$ \\
\hline
\end{tabular}

Table 5. Immunoreactivity of nesfatin-1 located in particular zones of the distal femoral growth cartilage of the femur of female rats in conditions of developing osteopenia

\begin{tabular}{llccc}
\hline \multirow{2}{*}{ Layers of growth cartilage } & \multicolumn{3}{c}{ Groups } \\
\cline { 2 - 5 } & & SHO & OVX-PhS & OVX-NES \\
\hline \multirow{2}{*}{ Resting zone } & intracellularly & + & $+/-$ & $+/-$ \\
\cline { 2 - 5 } & extracellularly & + & $+/-$ & ++ \\
\hline \multirow{2}{*}{ Proliferation zone } & intracellularly & + & + & + \\
\cline { 2 - 5 } & extracellularly & + & ++ & ++ \\
\hline \multirow{2}{*}{ Hypertrophic zone } & intracellularly & + & + & $+/-$ \\
\cline { 2 - 5 } & extracellularly & $+/-$ & + & $+/-$ \\
\hline \multirow{2}{*}{ Calcifying zone } & intracellularly & ++ & +++ & ++ \\
\cline { 2 - 5 } & extracellularly & ++ & +++ & ++ \\
\hline
\end{tabular}

Data are mean \pm S.E.M for 7 animals. (+/-) slight immunoreactivity of nesfatin-1, (+) medium immunoreactivity, (++) high immunoreactivity, (+++) very high immunoreactivity

tibia ultimate strength and work-to-ultimate strength ratio parameters were observed in the OVX-PhS group (Tab. 4). The OVX-NES females did not show statistically significant differences in the ultimate strength and work-to-ultimate strength ratio in relation to the other groups (Tab. 4), but nesfatin-1 administration caused a statistically insignificant increase in the values of these parameters compared to the OVX-PhS group.

The semi-quantitative method was used to assess the immunoreactivity of nesfatin-1 in the individual layers of the growth cartilage of the distal metaphysis of the femur. A positive immunohistochemical reaction for nesfatin-1 located intracellularly as well as extracellularly was observed in all zones of the growth cartilage, but its severity varied from (-/+) to $(+++)$ (Fig. 1, Tab. 5). The strongest immunohistochemical reaction for nesfatin-1 was observed in the calcifying zone in all groups. Furthermore, the highest immunoreactivity of nesfatin-1 (+++) distributed intra- and extracellularly was found in the OVX-PhS group (Fig. 1, Tab. 5).

The ovariectomy significantly increased $(\mathrm{P} \leq 0.05)$ the serum osteocalcin level (Tab. 6), which was the highest in animals from the OVX-NES group $(\mathrm{P} \leq 0.05)$. The lowest serum bALP concentration, in comparison to the other groups $(\mathrm{P} \leq 0.05)$, was noted in OVX-PhS group $(26.8 \%$ vs. SHO, 36.4\% vs. OVX-NES). The bALP concentration in the SHO and OVX-NES groups did not differ significantly. The NTx concentration exhibited the highest values of this parameter in the OVX-PhS group. A statistically $(\mathrm{P} \leq 0.05)$ lower concentration of NTx, compared to the OVX-PhS group, was found in the $\mathrm{SHO}$ group (by $25.8 \%$ ). In the OVXNES group, the NTx concentration was by $11.16 \%$ higher than in the OVX-PhS group, but these changes were statistically insignificant (Tab. 6).

Table 6. Concentration of osteocalcin, bone alkaline phosphatase (bALP) and N-terminal crosslinked telopeptide alpha type I collagen (NTx) in serum of female rats in conditions of developing osteopenia

\begin{tabular}{cccc}
\hline Parameters & SHO & OVX-PhS & OVX-NES \\
\hline Osteocalcin $(\mathrm{ng} / \mathrm{ml})$ & $2.61 \pm 0.229$ & $3.74 \pm 0.133^{*}$ & $5.31 \pm 0.301 * 5$ \\
\hline $\mathrm{bALP}(\mathrm{ng} / \mathrm{ml})$ & $11.38 \pm 0.626$ & $8.33 \pm 0.315^{*}$ & $13.10 \pm 1.157^{\S}$ \\
\hline $\mathrm{NTx}(\mathrm{nmol} / \mathrm{ml})$ & $20.18 \pm 1.434$ & $25.39 \pm 0.605^{*}$ & $22.84 \pm 1.038$ \\
\hline
\end{tabular}

Data are mean \pm S.E.M for 7 animals. Statistical significance is indicated as ${ }^{*} \mathrm{P}<0.05$ vs. SHO; ${ }^{\S}$ vs. OVX-PhS at $\mathrm{P} \leq 0.05$ 

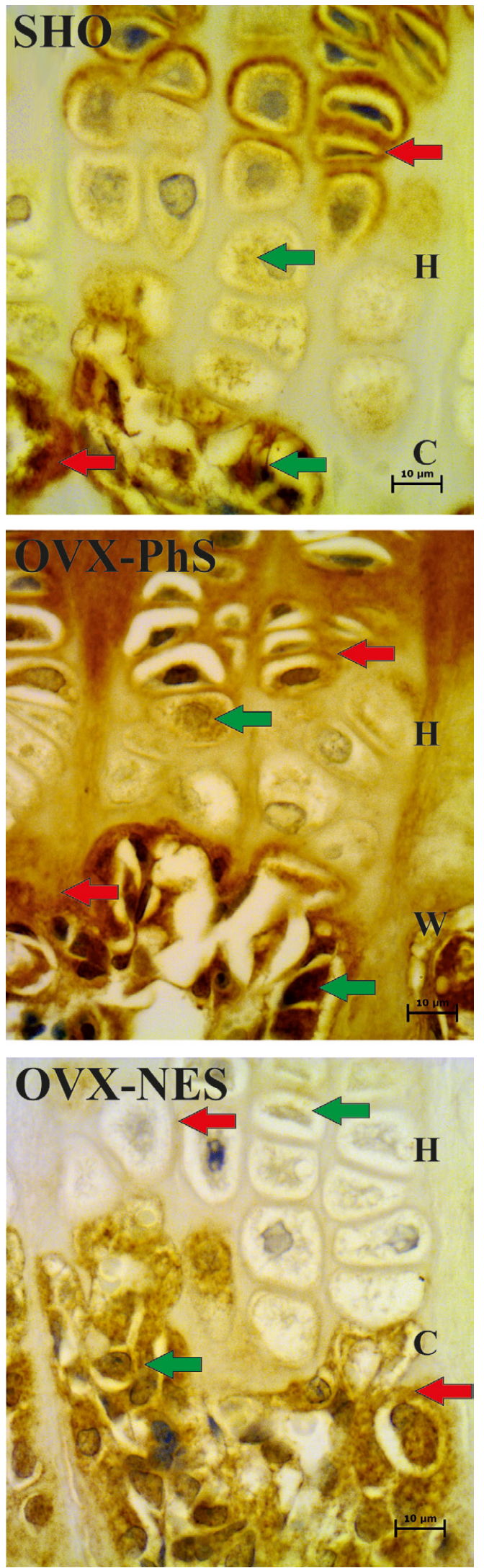

Figure 1. Immunohistochemical localization of nesfatin-1 (brown colour) in fragments of distal growth cartilage of femur in SHO rats receiving PhS (SHO group), and ovariectomized rats receiving $\mathrm{PhS}$ (OVX-PhS group) or nesfatin-1 (OVX-NES group). Localization of nesfatin-1: extracellular - red arrow, and intracellular - green arrow; $\mathrm{H}$ - hypertrophic zone, $\mathrm{C}$ - calcifying zone (mag. 400x)

\section{DISCUSSION}

This study attempts to determine the effect of nesfatin-1 on the metabolism and properties of bone in female rats with elimination of gonadal hormonal function as a result of ovariectomy. The evaluation of the effects of nesfatin-1 was carried out in the conditions of developing osteopenia. The ovariectomized female rats used in the experimental system are one of the classic animal models used to induce osteopenia, and ovariectomy is a recognized procedure in OP trials [27, 28]. Nevertheless, although the model of ovariectomized rats is the 'golden standard' in experimental animal models for OP trials $[29,30,31]$, it has several disadvantages, such as the failure to achieve full skeletal maturity and the low rate of remodeling of the cortical bone [32, 33].

Natural menopause is associated with a decrease in the level of circulating estrogens [34-36], and one of the effects of diminution in their concentration is the increase in BW [37]. Similar effects are also observed in laboratory animals after gonadectomy $[38,39,40]$. The present investigations also showed a significant increase in BW in the ovariectomized females in the conditions of developing osteopenia in comparison with the $\mathrm{SHO}$ group. The increase in $\mathrm{BW}$ of the OVX animals was accompanied by a statistically significant increase in FM, compared to the SHO group. These changes in BW in the ovariectomized animals were a result of fat deposition caused by estrogen deficiency [41]. In a human study, a correlation between menopausal transition and an increase in total and visceral adipose tissue has also been observed $[42,43,44]$.

Control of BW includes the impact of many different factors, such as genes, central nervous system functions, nutrition, physical exercise, hormones, and adipokines [45, $46,47,48]$. Adipokines are secretory factors derived from adipose tissue, and this group also includes nesfatin-1. Oh-I et al. [18], who first described this peptide, found that the intracerebroventricular administration of nesfatin-1 reduces food intake in a dose-dependent manner and inhibits weight gain in rats. These results have been confirmed and extended by data provided by several independent groups of researchers showing the anorexigenic effect of nesfatin-1 after injection into the lateral, third, fourth ventricles of the brain, cisterna magna, or directly to paraventricular nucleus, lateral hypothalamic nucleus, dorsal motor nuclei of the vagus nerve in mice $[49,50]$, rat $[51,52,53,54]$, and goldfish $[55,56]$. Nesfatin-1 administered to the lateral ventricle of rat brain reduced food intake with delay (during the third hour after administration), and the anorexigenic effect persisted for a relatively long time $(6-48 \mathrm{~h})[57,58]$. In turn, the intracerebroventricular nesfatin- 1 administration to mice delayed the anorexigenic effect of this peptide (2 $\mathrm{h}$ ) and the duration of its action was $8 \mathrm{~h}$ [49]. It is highly probable that different microstructures are involved in these anorexigenic interactions in various animal species, which may additionally have different sensitivity to nesfatin-1. This is indicated by the fact that intracerebroventricular administration of nesfatin-1 to mice resulted in decreased food intake during the dark phase by reducing the size of the meal and prolonging the intervals between meals [50]. However, after intracerebroventricular administration of the central fragment of nesfatin-1 to rats, the observed reduction in food intake was only associated with prolongation of the intervals between meals [19]. 
The anorexigenic effect of nesfatin-1 was also observed after its peripheral administration. Intraperitoneal injection of nesfatin-1 in a dose-dependent manner inhibited food intake for 3 hours in the dark phase in mice, whereas the subcutaneous injection resulted in prolongation of its anorexigenic action for up to 14 hours [59]. In the authors' studies, the intraperitoneally administered nesfatin-1 to ovariectomized rats did not significantly affect their BW, compared to the OVX-PhS animals. However, it should be remembered that nesfatin-1 in the current study was administered at the same time in the morning.

Elimination of the ovary function increases the rate of bone remodeling and imbalances between bone formation and bone resorption, with predominance of the latter process. In the presented study, the results of the densitometric tests showed that the elimination of endocrine ovarian function by ovariectomy resulted in a reduction in $\mathrm{tBMD}, \mathrm{BMD}$, and BMC values of the femur and tibia. This indicates predominance of resorption over bone formation. The authors' observations are confirmed by the results obtained by other authors who performed studies on the model of ovariectomized animals $[40,60,61,62]$. A decrease in the value of densitometric parameters was also observed in clinical trials in postmenopausal women $[63,64]$. In the current study, it was shown that the administration of nesfatin-1 positively affects the densitometry parameters of bone tissue. The BMC and BMD values of tibia after nesfatin-1 administration were higher by $6.9 \%$ and $6.8 \%$, respectively, than in the OVX-PhS group. The BMD and BMC values of femurs did not show statistically significant differences between the ovariectomized groups; however, the values of these parameters in the OVN-NES group were higher by $2.5 \%$ and $5 \%$, respectively, in relation to the OVX-PhS group. Moreover, the results noted in the OVX-NES group did not differ statistically from those in the control group.

Only one research team has previously attempted to determine the effect of nesfatin-1 on DXA parameters in conditions of sex hormone deficiency [25]. Intravenous administration of nesfatin-1 in established osteopenia resulted in an increase in BMD of the lumbar vertebrae and femur in OVX rats. The increase in DXA parameters values found in the present and aforementioned study, which is a consequence of intensification of bone formation and mineralization, is most likely an effect of direct interaction of nesfatin-1 on osteoblasts (OB). Li et al. [25] demonstrated in vitro expression of nesfatin-1/NUCB2 mRNA in osteoblast line cells, as well as a promising effect of this hormone on mineralization.

The effect of other adipokines on DXA parameters is not entirely clear. For example, a positive relationship between leptin and BMD values in postmenopausal women was demonstrated by Thomas et al. [65], Yamauchi et al. [66], Blain et al. [67], and Roux et al. [68]. Nevertheless, there are also results that indicate negative or no correlations between the concentration of leptin and BMD of bone tissue $[12,69,70,71]$. Wang et al. [15], who compared the effect of ovariectomy on BMD and strength parameters of bone tissue in adiponectin-deficient mice and wild-type mice, showed that adiponectin deficiency was protective against the development of osteoporotic changes. No significant relationships among other adipokines, i.e. apelin, resistin and visfatin, and bone DXA parameters, were found by Peng et al. [12] and Zhang et al. [17].
Peripheral quantitative computed tomography (pQCT) facilitates detailed examination of skeleton parameters. In addition, pQCT provides separate assessment of trabecular and cortical bone parameters, which allows accurate examination of the distribution of bone tissue, as well as its architecture and geometry, especially in areas susceptible to fractures [72]. The results obtained in the current study showed that the ovariectomy did not significantly affect the majority of bone parameters measured in the mid-length of the femoral and tibial shaft in the female rats in the conditions of developing osteopenia. These observations confirm the results obtained by other authors [73, 74]. In the presented study, statistically significant differences were observed only for the femur CtBMD, when the ovariectomy significantly reduced the value of this parameter. The use of nesfatin-1 markedly improved the CtBMD values, which were close to the values found in the SHO animals. On the other hand, tomographic examination of the distal part of femur and proximal part of tibia showed a significant reduction of the parameters determined for the total bone cross-section, i.e. TotBMC and TotvBMD, and trabecular bone tissue (TbBMC and TbBMD), in the OVX rats. In turn, administration of nesfatin-1 caused a significant increase in the TotvBMD and TbBMD values of the femur and tibia, compared to the OVX-PhS group, which indicates its protective function in the development of atrophic changes.

In the available literature, there are no studies indicating a relationship between nesfatin-1 administration and tomographic parameters of bone tissue, while there are reports on the effects of other adipokines; however, they are ambiguous and often present opposite results. A low bone mass combined with the reduction of the values of tomographic parameters was observed by Williams et al. [13] in $o b / o b$ and $d b / d b$ mice. In turn, adiponectin deficiency in young and adult mice caused positive changes in the values of tomographic parameters, i.e. an increase in bone mass, trabecular bone volume, and the number of bone trabeculae [14]. On the other hand, administration of adiponectin to mice caused growth of trabecular bone mass combined with a decline in the OC number [11]. The positive effect of adiponectin on bone tissue manifested by an increase in trabecular bone mass, a decrease in the OC number and bone resorption was also found in transgenic animals with adiponectin overexpression [16].

The results of mechanical analysis of bones confirm the results of densitometric and tomographic examinations that predict mechanical strength. It has been shown that ovariectomy resulted in a decrease in the strength parameters of the femur and tibia, i.e. the ultimate strength and workto-ultimate strength ratio. The results reported by other authors also indicate a negative effect of gonadectomy on the mechanical features of bone [75]. On the other hand, the nesfatin-1 administration to the OXV females limited the negative effects of sex hormone deficiency on bone metabolism, which was reflected in the increase in the strength parameters. The administration of nesfatin-1 to the OVX animals had the strongest influence on the ultimate strength values of the femur, which increased in comparison with OVX-PhS, approaching the results obtained in SHO.

The immunohistochemical analysis showed intra- and extracellular localization of nesfatin-1 in all layers of growth cartilage of the distal metaphysis of the femur of the female rats. These results are in part a confirmation of previous 
reports by Petersson et al. [76], who were the first to report that the NUCB protein, which later turned out to be a precursor to nesfatin-1, exhibited intra- and extracellular localization within the bone tissue. As demonstrated by Petersson et al. [76], the NUCB expression was relatively low during cell proliferation, increased during matrix differentiation and maturation, and then decreased during the mineralization process [76]. The results of the current study are in agreement with these findings. It was found that the intensity of the immunohistochemical reaction for nesfatin-1 enhanced with the increase in the degree of chondrocyte maturity, and the highest intensity of the reaction was noted in the calcifying zone. This suggests that nesfatin-1 may act as a modulator of maturation of the matrix in the bone mineralization process and is in line with previous assumptions [76]. This role of nesfatin-1 was confirmed by Li et al. [25], who found its stimulated effect on in vitro mineralization. Increased expression of nesfatin-1 during the maturation of chondrocytes was also observed by Scotece et al. [24] in in vitro studies performed on the chondrogenic ATDC-5 cell line.

An important indicator of processes occurring in bone tissue during the development and involution of the skeleton, as well as in metabolic diseases, facilitating characterization and determination of the intensity of changes related to bone formation and resorption, include biochemical indicators of bone tissue metabolism, referred to as bone metabolism markers. These are chemical compounds released from $\mathrm{OB}$ and OC or collagen metabolism products $[77,78]$. In the present research, three markers of bone metabolism were used: osteocalcin, bALP, and NTx. Osteocalcin is a specific noncollagen protein of the bone matrix synthesized by mature $\mathrm{OB}$, odontoblasts, and hypertrophic chondrocytes. It is a recognized indicator of bone formation and metabolic activity of $\mathrm{OB}[77,78]$. An increase in the osteocalcin concentration is observed in peri- and postmenopausal women and in diseases associated with increased bone turnover, such as OP or Paget's disease $[79,80]$. In the present studies, there was an increase in the osteocalcin concentration in the serum of both OVX groups. Similar results were observed by other authors who conducted studies on the model of OVX rats $[75,81]$. The highest values of this parameter were noted after nesfatin-1 treatment - an increase by $103 \%$.

Bone alkaline phosphatase, like osteocalcin, is produced by $\mathrm{OB}$, and an increase in its concentration may indicate increased metabolism of these cells and intensification of bone formation and mineralization $[77,78]$. In the presented study, the bALP concentration decreased in OVX-PhS compared to SHO, whereas the administration of nesfatin-1 induced an increase in the bALP serum concentration in rats undergoing ovariectomy, compared to the $\mathrm{SHO}$ group (by $15.1 \%$ ). The obtained results were in agreement with previous observations reported by Li et al. (2013). These authors demonstrated a dose-dependent effect of nesfatin-1 on the increase in bALP activity in a mouse model of MC3T3-E1 preosteoblastic cells, but only in combination with rhBMP2 (recombinant human bone morphogenetic protein 2). Oshima et al. [11] demonstrated in in vitro studies that another adipokine - adiponectin, influences the increase in the ALP mRNA expression in preosteoblastic murine MC3T3-E1 cells. An increase in the bALP concentration in the serum after ovariectomy was also observed, while leptin administration limited this increase [82].
In the presented study, the intensity of osteoclastic bone resorption was assessed based on the NTx serum concentration. Ovariectomy significantly increased the NTx concentration compared to the SHO animals. Increased serum NTx levels due to osteoclastic bone resorption were previously documented in studies on ovariectomized rats [81, 83]. The increase in NTx has also been confirmed in clinical trials in women [84]. There are no papers in the literature describing the effect of nesfatin-1 on the NTx concentration, while the analysis of the results of the current study showed that intraperitoneal administration of nesfatin-1 caused a decrease in the NTx concentration, compared to OVXPhS. Nevertheless, the NTx concentration in animals with developing osteopenia receiving nesfatin-1, was statistically insignificant compared to the SHO and OVX-PhS rats, although a downward trend was observed.

Analysis of the bone metabolism markers confirmed the negative effect of surgical elimination of endocrine function of ovaries on bone metabolism. The increase in the NTx and osteocalcin concentration in combination with the decrease in the bALP concentration in the OVX-PhS animals unambiguously indicated an increase in bone turnover, with strong stimulation of bone resorption. In turn, the increase in the bALP concentration, together with the increase in the osteocalcin concentration after nesfatin-1 administration in conditions of steroid hormone deficiency, demonstrated increased metabolic activity of $\mathrm{OB}$ with subsequent intensification of bone formation and mineralization. The simultaneous decrease in the NTx concentration may indicate an inhibitory role of nesfatin-1 in the osteoclastic bone resorption. However, the dominant effect of nesfatin-1 interaction, assessed on the basis of bone markers in the serum, appears to stimulate bone formation and mineralization. This is confirmed by the changes in the densitometric, tomographic, and strength parameters of bones, which are a reflection of the predominance of osteosynthesis over bone resorption.

The positive changes in the densitometric, tomographic and mechanical parameters resulting from the increase in osteosynthesis and mineralization after the nesfatin-1 administration, indicate that this hormone mediates these processes. This is confirmed by the increase in the intensity of the immunohistochemical reaction for nesfatin-1 in the growth plate, along with the increase in the degree of chondrocyte maturity. The highest intensity of immunohistochemical reaction observed in the calcifying zone confirmed the earlier suggestions that nesfatin-1 may act as a modulator of maturation of the matrix in bone mineralization. The changes in the bone metabolism markers after the nesfatin-1 administration prove these findings.

Unfortunately, the presented study also has some limitations, the main one certainly being the lack of nesfatin-1 serum concentration before and at the end of the experiment. Therefore, the assessment of possible changes in the concentration of nesfatin-1 should be the goal of further studies.

\section{CONCLUSION}

The results of the presented research indicate that nesfatin-1 is a physiological factor that mediates bone metabolism. Moreover, nesfatin-1 exerts a protective effect on bone tissue properties in rats in the conditions of developing osteopenia. The comprehensive assessment of bone tissue parameters 
using recognized methods guarantees reliability of the results, which may be the basis for further research in the field of basic and clinical sciences. Since osteoporosis is now a global problem, the proposed research is of great health, social, and economic importance.

\section{REFERENCES}

1. Qaseem A, Forciea MA, McLean RM, Denberg TD. Clinical Guidelines Committee of the American College of Physicians. Treatment of low bone density or osteoporosis to prevent fractures in men and women: a clinical practice guideline update from the American College of Physicians. Ann Intern Med. 2017; 166(11): 818-839.

2. Levin VA, Jiang X, Kagan R. Estrogen therapy for osteoporosis in the modern era. Osteoporos Int. 2018; 29(5): 1049-1055.

3. Hughes DE, Dai A, Tiffee JC, Mundy GR, Boyce BF. Estrogen promotes apoptosis of murine osteoclasts mediated by TGF-beta. Nat Med. 1996; 2(10): 1132-1136.

4. Eriksen EF, Langdahl B, Vesterby A, Rungby J, Kassem M. Hormone replacement therapy prevents osteoclastic hyperactivity: a histomorphometric study in early postmenopausal women. J Bone Miner Res. 1999; 14(7): 1217-1221.

5. Fox C, Edwards MH, Dennison EM, Cooper C. Personal and societal burden of osteoporotic fractures. Clinic Rev Bone Miner Metab. 2015; 13(2): 53-60.

6. Hernlund E, Svedbom A, Ivergård M, Compston J, Cooper C, Stenmark J, McCloskey EV, Jönsson B, Kanis JA. Osteoporosis in the European Union: medical management, epidemiology and economic burden. A report prepared in collaboration with the International Osteoporosis Foundation (IOF) and the European Federation of Pharmaceutical Industry Associations (EFPIA). Arch Osteoporos. 2013; 8: 136.

7. Kanis JA, Hiligsmann M. The application of health technology assessment in osteoporosis. Best Pract Res Clin Endocrin Metab. 2014; 28(6): 895-910.

8. Bartell SM, Rayalam S, Ambati S, Gaddam DR, Hartzell DL, Hamrick M, She JX, Della-Fera MA, Baile CA. Central (ICV) leptin injection increases bone formation, bone mineral density, muscle mass, serum IGF-1, and the expression of osteogenic genes in leptin-deficient ob/ ob mice. J Bone Miner Res. 2011; 26(8): 1710-1720.

9. Ducy P, Amling M, Takeda S, Priemel M, Schilling AF, Beil FT, Shen J, Vinson C, Rueger JM, Karsenty G. Leptin inhibits bone formation through a hypothalamic relay: a central control of bone mass. Cell. 2000; 100(2): 197-207.

10. Luo E, Hu J, Bao C, Li Y, Tu Q, Murray D, Chen J. Sustained release of adiponectin improves osteogenesis around hydroxyapatite implants by suppressing osteoclast activity in ovariectomized rabbits. Acta Biomat. 2012; 8(2): 734-743.

11. Oshima K., Nampei A, Matsuda M, Iwaki M, Fukuhara A, Hashimoto J, Yoshikawa H, Shimomura I. Adiponectin increases bone mass by suppressing osteoclast and activating osteoblast. Biochem Biophys Res Commun. 2005; 331(2): 520-526.

12. Peng X D, Xie H, Zhao Q, Wu XP, Sun ZQ, Liao EY. Relationships between serum adiponectin, leptin, resistin, visfatin levels and bone mineral density, and bone biochemical markers in Chinese men. Clin Chim Acta. 2008; 387(1-2): 31-35.

13. Williams GA, Callon KE, Watson M, Costa JL, Ding Y, Dickinson M, Wang Y, Naot D, Reid IR, Cornish J. Skeletal phenotype of the leptin receptor-deficient $\mathrm{db} / \mathrm{db}$ mouse. J Bone Miner Res. 2011; 26(8): 1698-1709.

14. Williams GA, Wang Y, Callon KE, Watson M, Lin JM, Lam JB, Costa JL, Orpe A, Broom N, Naot D, Reid IR, Cornish J. In vitro and in vivo effects of adiponectin on bone. Endocrinol. 2009; 150(8): 3603-3610.

15. Wang F, Wang PX, Wu XL, Dang SY, Chen Y, Ni YY, Gao LH, Lu SY, Kuang Y, Huang L, Fei J, Wang ZG, Pang XF. Deficiency of adiponectin protects against ovariectomy - induced osteoporosis in mice. PLoS One 2013; 8(7): e68497.

16. Yamaguchi N, Kukita T, Li YJ, Kamio N, Fukumoto S, Nonaka K, Ninomiya Y, Hanazawa S, Yamashita Y. Adiponectin inhibits induction of TNF-alpha/RANKL-stimulated NFATc1 via the AMPK signaling. FEBS Lett. 2008; 582(3): 451-456.

17. Zhang H, Xie H, Zhao Q, Xie G-Q, Wu X-P, Liao E-Y, Luo X-H. Relationships between serum adiponectin, apelin, leptin, resistin, visfatin levels and bone mineral density, and bone biochemical markers in postmenopausal Chinese women. J Endocrinol Invest. 2010; 33(10): 707-711.
18. Oh-I S, Shimizu H, Satoh T, Okada S, Adachi S, Inoue K, Eguch H, Yamamoto M, Imaki T, Hashimoto K, Tsuchiya T, Monden T, Horiguchi $\mathrm{K}$, Yamada M, Mori M. Identification of nesfatin-1 as a satiety molecule in the hypothalamus. Nature 2006; 443(7112): 709-712.

19. Stengel A, Goebel-Stengel M, Wang L, Kato I, Mori M, Tache Y. Nesfatin- $1_{30-59}$ but not the N- and C-terminal fragments, nesfatin- $1_{1-29}$ and nesfatin-1 $1_{60-82}$ injected intracerebroventricularly decreases dark phase food intake by increasing inter-meal intervals in mice. Peptides. 2012; 35(2): 143-148.

20. Jiang L, Bao J, Zhou X, Xiong Y, Wu L. Increased serum levels and chondrocyte expression of nesfatin-1 in patients with osteoarthritis and its relation with BMI, hsCRP, and IL-18. Mediators Inflamm. 2013; 631251 .

21. Zhang Y, Shui X, Lian X, Wang G. Serum and synovial fluid nesfatin-1 concentration is associated with radiographic severity of knee osteoarthritis. Med Sci Monit. 2015; 21:1078-1082.

22. Pearle AD, Scanzello CR, George S, Mandl LA, DiCarlo EF, Peterson $\mathrm{M}$, Sculco TP, Crow MK. Elevated high sensitivity C-reactive protein levels are associated with local inflammatory findings in patients with osteoarthritis. Osteoarth Cartil. 2007; 15(5): 516-523.

23. Inoue $\mathrm{H}$, Hiraoka $\mathrm{K}$, Hoshino $\mathrm{T}$, Okamoto $\mathrm{M}$, Iwanaga $\mathrm{T}$, Zenmyo $\mathrm{M}$, Shoda T, Aizawa H, Nagata K. High levels of serum IL-18 promote cartilage loss through suppression of aggrecan synthesis. Bone 2008; 42(6): 1102-1110.

24. Scotece M, Conde J, Abella V, Lopez V, Lago F, Pino J, Gomez-Reino JJ, Gualillo O. NUCB2/nesfatin: A new adipokine expressed in human and murine chondrocytes with pro-inflammatory properties, an in vitro study. J Ortho Res. 2014; 32(5): 653-660.

25. Li R, Wu Q, Zhao Y, Jin W, Yuan X, Wu X, Tang Y, Zhang J, Tan X, Bi F, Liu J-N. The novel pro-osteogenic activity of NUCB2. PLoS ONE 2013; 8(4): e61619.

26. Ferretti JL, Capozza RF, Mondelo N, Montuori E, Zanchetta JR. Interrelationships between densitometric, geometric and mechanical properties of rat femora: inferences concerning mechanical regulation of bone modeling. J Bone Min Res. 1993; 8(11): 1389-1395.

27. Wronski TJ, Dann LM, Scott KS, Cintrón M. Long-term effects of ovariectomy and aging on the rat skeleton. Calcif Tissue Int. 1989; 45(6): 360-366.

28. Riggs BL, Melton LJ. The prevention and treatment of osteoporosis. N Engl J Med. 1992; 327(9): 620-627.

29. Kalu DN. The ovariectomized rat model of postmenopausal bone loss. Bone Miner. 1991; 15(3): 175-191.

30. Frost HM, Jee WS. On the rat model of human osteopenias and osteoporoses. Bone Miner. 1992; 18(3): 227-236.

31. Lelovas PP, Xanthos TT, Thoma SE, Lyritis GP, Dontas IA. The laboratory rat as an animal model for osteoporosis research. Comp Med. 2008; 58(5): 424-430.

32. Rodgers JB, Monier-Faugere MC, Malluche H. Animal models for the study of bone loss after cessation of ovarian function. Bone. 1993; 14(3): 369-77.

33. Mosekilde L. Assessing bone quality - animal models in preclinical osteoporosis research. Bone 1995; 17(4 Suppl): 343S-352S.

34. Morrison JH, Brinton RD, Schmidt PJ, Gore AC. Estrogen, menopause, and the aging brain: how basic neuroscience can inform hormone therapy in women. J Neuros. 2006; 26(41): 10332-10348.

35. Weitzmann MN, Pacifici R. Estrogen deficiency and bone loss: An inflammatory tale. J Clin Invest. 2006; 116(5): 1186-1194.

36. Gallagher JC. Effect of early menopause on bone mineral density and fractures. Menopause. 2007; 14(3 Pt 2): 567-571.

37. Freeman EW, Sammel MD, Lin H, Gracia CR. Obesity and reproductive hormone levels in the transition to menopause. Menopause. 2010; 17(4): 718-726.

38. Burguera B, Hofbauer LC, Thomas T, Gori F, Evans GL, Khosla S, Riggs $\mathrm{BL}$, Turner RT. Leptin reduces ovariectomy-induced bone loss in rats. Endocrinol. 2001; 142(8): 3546-3553.

39. Kamei Y, Suzuki M, Miyazaki H., Tsuboyama-Kasaoka N, Wui J, Ishimi Y, Ezaki O. Ovariectomy in mice decreases lipid metabolism-related gene expression in adipose tissue and skeletal muscle with increased body fat. J Nutr Sci Vitaminol. 2005; 51(2): 110-117.

40. Gomes RM, Ferreira MD Junior, Francisco FA, Moreira VM, de Almeida DL, Saavedra LPJ, de Oliveira JC, da Silva Franco CC, Pedrino GR, de Freitas Mathias PC, Natali MRM, Dias MJ, de Morais IJ, de MoraesSMF. Strength training reverses ovariectomy-induced bone loss and improve metabolic parameters in female Wistar rats. Life Sci. 2018; 213: 134-141.

41. Zhao X, Wu Z, Zhang Y, Yan Y, He Q, Cao P, Lei W: Anti-osteoporosis activity of Cibotium barometz extract on ovariectomy-induced bone loss in rats. J Ethnopharmacol. 2011; 137(3): 1083- 1088. 
42. Lovejoy JC, Champagne CM, de Jonge L, Xie H, Smith SR. Increased visceral fat and decreased energy expenditure during the menopausal transition. Int J Obes (Lond). 2008; 32(6): 949-958.

43. Ho SC, Wu S, Chan SG, Sham A. Menopausal transition and changes of body composition: a prospective study in Chinese perimenopausal women. Int J Obes (Lond). 2010; 34(8): 1265-1274.

44. Abdulnour J, Doucet E, Brochu M, Lavoie J-M, Strychar I, RabasaLhoret R, Prud'homme D. The effect of the menopausal transition on body composition and cardiometabolic risk factors: a Montreal-Ottawa New Emerging Team group study. Menopause. 2012; 19(7): 760-767.

45. Maes HH, Neale MC, Eaves LJ. Genetic and environmental factors in relative body weight and human adiposity. Behav Genet. 1997; 27(4): 325-351.

46. Morton GJ, Cummings DE, Baskin DG, Barsh GS, Schwartz MW. Central nervous system control of food intake and body weight. Nature. 2006; 443(7109): 289-295.

47. Willer CJ, Speliotes EK, Loos RJF, Li S, Lindgren CM, Heid IM, Berndt SI, Elliott AL, Jackson AU, Lamina C, Lettre G, et al. Six new loci associated with body mass index highlight a neuronal influence on body weight regulation. Nat Genet. 2009: 41(1): 25-34.

48. Jung UJ, Choi M-S. Obesity and its metabolic complications: The role of adipokines and the relationship between obesity, inflammation, insulin resistance, dyslipidemia and nonalcoholic fatty liver disease. Int J Mol Sci. 2014; 15(4): 6184-6223.

49. Atsuchi K, Asakawa A, Ushikai M, Ataka K, Tsai M, Koyama K, Sato Y, Fujimiya M, Inui A. Centrally administered nesfatin-1 inhibits feeding behaviour and gastroduodenalmotility in mice. Neuroreport. 2010; 21(15): 1008-1011.

50. Goebel-Stengel M, Wang L, Stengel A, Tache Y. Localization of nesfatin-1 neurons in the mouse brain and functional implication. Brain Res. 2011; 1396: 20-34.

51. Yosten GL, Samson WK. Nesfatin-1 exerts cardiovascular actions in brain: possible interaction with the central melanocortin system. Am J Physiol Regul Integr Comp Physiol. 2009; 297(2): R330-R336.

52. Chen X, Dong J, Jiang ZY. Nesfatin-1 influences the excitability of glucosensingneurons in the hypothalamic nuclei and inhibits the food intake. Regul Pept. 2012; 177(1-3): 21-26.

53. Moreau JM, Ciriello J. Nesfatin-1 induces Fos expression and elicits dipsogenic responses in subfornical organ. Behav Brain Res. 2013; 250: $343-350$

54. Dong J, Guan HZ, Jiang ZY, Chen X. Nesfatin-1 influences the excitability of glucosensing neurons in the dorsal vagal complex and inhibits food intake. PLoS ONE 2014; 9(6): e98967.

55. Gonzalez R, Kerbel B, Chun A, Unniappan S. Molecular, cellular and physio-logical evidences for the anorexigenic actions of nesfatin-1 in goldfish. PLoS ONE 2010; 5(12): e15201.

56. Kerbel B, Unniappan S. Nesfatin-1 suppresses energy intake, co-localises ghrelin in the brain and gut, and alters ghrelin, cholecystokinin and orexin mRNA expression in goldfish. J Neuroendocrinol. 2012; 24(2): 366-377.

57. Bloem B, Xu L, Morava E, Faludi G, Palkovits M, Roubos EW, Kozicz T. Sex specific differences in the dynamics of cocaine- and amphetamineregulated tran-script and nesfatin-1 expressions in the midbrain of depressed suicide victims vs. controls. Neuropharmacol. 2012; 62: 297-303.

58. Konczol K, Pinter O, Ferenczi S, Varga J, Kovacs K, Palkovits M, Zelena D, Toth ZE. Nesfatin-1 exerts long-term effect on food intake and body temperature. Int J Obes. 2012; 36(12): 1514-1521.

59. Shimizu H, Oh-I S, Hashimoto K, Nakata M, Yamamoto S, Yoshida N, Eguchi H, Kato I, Inoue K, Satoh T, Okada S, Yamada M, Yada T, Mori M. Peripheral administration of nesfatin-1 reduces food intake in mice: the leptin-independent mechanism. Endocrinol. 2009; 150(2): 662-671.

60. Jiang S-D, Shen C, Jiang L-S, Dai L-Y. Differences of bone mass and bone structure in osteopenic rat models caused by spinal cord injury and ovariectomy. Osteoporos Int. 2007; 18(6): 743-750.

61. Baofeng L, Zhi Y, Bei C, Guolin M, Qingshui Y, Jian L. Characterization of a rabbit osteoporosis model induced by ovariectomy and glucocorticoid. Acta Orthop. 2010; 81(3): 396-401.

62. Hernandes L, Ramos AL, Micheletti KR, Santi AP, Cuoghi OA, Salazar M. Densitometry, radiography, and histological assessment of collagen as methods to evaluate femoral bones in an experimental model of osteoporosis. Osteoporos Int. 2012; 23(2): 467-473.

63. Cipriani C, Pepe J, Bertoldo F, Bianchi G, Cantatore FP, Corrado A, Di Stefano M, Frediani B, Gatti D, Giustina A,Porcelli T, Isaia G. Rossini M,Nieddu L, Minisola S, Girasole G, Pedrazzoni M. The epidemiology of osteoporosis in Italian postmenopausal women according to the National Bone Health Alliance (NBHA) diagnostic criteria: a multicenter cohort study. J Endocrinol Invest. 2018; 41(4): 431-438.

64. Urano T, Shiraki M, Kuroda T, Tanaka S, Urano F, Uenishi K, Inoue S. Bisphosphonates prevent age-related weight loss in Japanese postmenopausal women. J Bone Min Met. 2018; 36(6):734-740.

65. Thomas T, Burguera B, Melton LJ III, Atkinson E J, O'Fallon WM, Riggs BL, Khosla S. Role of serum leptin, insulin, and estrogen levels as potential mediators of the relationship between fat mass and bone mineral density in men versus women. Bone. 2001; 29(2): 114-120.

66. Yamauchi M, Sugimoto T, Yamaguchi T, Nakaoka D, Kanzawa M, Yano S, Ozuru R, Sugishita T, Chihara K. Plasma leptin concentrations are associated with bone mineral density and the presence of vertebral fractures in postmenopausal women. Clin Endocrinol. 2001; 55(3): 341-347.

67. Blain H, Vuillemin A, Guillemin F, Durant R, Hanesse B, de Talance N, Doucet B, Jeandel C. Serum leptin level is a predictor of bone mineral density in postmenopausal women. J Clin Endocrinol Metab. 2002; 87(3): 1030-1035.

68. Roux C, Arabi A, Porcher R, Garnero P. Serum leptin as a determinant of bone resorption in healthy postmenopausal women. Bone. 2003; 33(5): 847-852.

69. Kontogianni MD, Dafni UG, Routsias JG, Skopouli FN. Blood leptin and adiponectin as possible mediators of the relation between fat mass and BMD in perimenopausal women. J Bone Miner Res. 2004; 19(4): 546-551.

70. Hipmair G, Bohler N, Maschek W, Soriguer F, Rojo-Martinez G, Schimetta W, Pichler R. Serum leptin is correlated to high turnover in osteoporosis. Neuro Endocrinol Lett. 2010; 31(1): 155-160.

71. Mohiti-Ardekani J, Soleymani-Salehabadi H, Owlia M, Mohiti A. Relationships between serum adipocyte hormones (adiponectin, leptin, resistin), bone mineral density and bone metabolic markers in osteoporosis patients. JBMM. 2014; 32(4): 400-404.

72. Stagi S, Cavalli L, Cavalli T, Martino M, Brandi ML. Peripheral quantitative computed tomography (pQCT) for the assessment of bone strength in most of bone affecting conditions in developmental age: a review. Ital J Pediatr. 2016; 42(1): 88.

73. Andersson N, Surve VV, Lehto-Axtelius D, Ohlsson C, Håkanson R, Andersson K, Ryberg B. Drug-induced prevention of gastrectomy- and ovariectomy-induced osteopaenia in the young female rat. J Endocrin. 2002; 175(3): 695-703.

74. Radzki RP, Bienko M, Wolski D, Lis A, Radzka A. Lipoic acid stimulates bone formation in ovariectomized rats in a dose-dependent manner. Can J Physiol Pharmacol. 2016; 94(9): 947-954.

75. Nian H, Ma MH, Nian SS, Xu LL. Antiosteoporotic activity of icariin in ovariectomized rats. Phytomed. 2009; 16(4): 320-326.

76. Petersson U, Somogyi E, Reinholt FP, Karlsson T, Sugars RV, Wendel M. Nucleobindin is produced by bone cells and secreted into the osteoid, with a potential role as a modulator of matrix maturation. Bone 2004; 34: 949-960.

77. Vasikaran SD. Utility of biochemical markers of bone turnover and bone mineral density in management of osteoporosis. Crit Rev Clin Lab Sci. 2008; 45(2): 221-258.

78. Kuo TR, Chen CH. Bone biomarker for the clinical assessment of osteoporosis: recent developments and future perspectives. Biomark Res. 2017; 5: 18.

79. Jagtap VR, Ganu JV, Nagane NS. BMD and serum intact osteocalcin in postmenopausal osteoporosis women. Indian J Clin Biochem. 2011; 26(1): 70-73.

80. Atalay S, Elci A, Kayadibi H, Onder CB, Aka N. Diagnostic utility of osteocalcin, undercarboxylated osteocalcin, and alkaline phosphatase for osteoporosis in premenopausal and postmenopausal women. Ann Lab Med. 2012; 32(1): 23-30.

81. Christopoulou GE, Stavropoulou A, Anastassopoulos G, Panteliou SD, Papadaki E, Karamanos NK, Panagiotopoulos E. Evaluation of modal damping factor as a diagnostic tool for osteoporosis and its relation with serum osteocalcin and collagen I N-telopeptide for monitoring the efficacy of alendronate in ovariectomized rats. J Pharm Biomed Anal. 2006; 41(3): 891-897.

82. Abdel-Sater KA, Mansour H. Bone biomarkers of ovariectomised rats after leptin therapy. Bratisl Lek Listy 2013; 114(6): 303-307.

83. Hou J-M, Xue Y, Lin Q-M. Bovine lactoferrin improves bone mass and microstructure in ovariectomized rats via OPG/RANKL/RANK pathway. Acta Pharmacol Sin. 2012; 33(10): 1277-1284.

84. Ardawi M-SM, Al-Kadi HA, Rouzi A A, Qari M H. Determinants of serum sclerostin in healthy pre- and postmenopausal women. JBMR. 2011; 26(12): 2812-2822. 